\title{
An Overview of Somatics (Body-Mind) Approaches in Dance Therapy
}

*Samson S. AKAPO

\begin{abstract}
Dance has been a huge part of the human cultures long before civilization, however, with time, extensive use of dance beyond entertainment and ritual evolved, one of which is dance therapy. Dance therapy, a branch of creative therapy, has been a very relevant field of study for quite some time. Aboriginals have always used this medium as a way to help individuals through physical, spiritual and psychological challenges which is evident in shamanistic practices. The field of dance therapy has been expanding and around WWII, the work of psychoanalytic pioneers such as Freud and Jung made their mark on it. Afterward, Mary Starks Whitehouse, who would become a Jungian analyst, developed a process called ñmovement-in-depthò based on her knowledge of dance, movement and depth psychology. This form of dance therapy is also known as áuthentic movementô a process where patients dance their feelings about an internal image that provides insight into issues in their past or current life. Somatic studies promote claims that the human body and mind work together to form a composite structure. Hence, somatic studies have had significant influence on dance since the 1970s when dancers and choreographers sought newer ways to incorporate ñbody-mind conceptò into dance training which has worked successfully in the area of therapy. Beyond its fundamental function, which is entertainment, this article explores the use of dance in therapeutic settings with emphasis on the approaches of two pioneers of dance therapy: Marian Chace and Mary Starks Whitehouse, stating how their works reside, particularly, within the confines of somatic studies.
\end{abstract}

*Samson S. AKAPO of the Department of Theatre Arts, University of Ibadan, Ibadan Email: akaposamson44@gmail.com 
Keywords: Dance, Somatics, Dance therapy, Marian Chace, Mary Starks Whitehouse,

\section{Introduction}

Eddy observes that ñsomatic studies also have been referred to as body therapies, bodywork, body-mind integration, body-mind disciplines, movement awareness, and movement (re) educationò (197). Dance serves many functions today for many people. It is entertainment, education and worship. Beyond these fundamental functions, dance serves other purposes in todayôs cultures and societies, both in health and wealth. Dance, in some cultures is a major part of religious liturgies and processions. People come together to create a dance for themselves or the divine. Through dances the religious aspect of a person or culture is projected through their movements. The creativity displayed in dance as an art form ultimately highlights the function of dance as an exposure and expression of the human body. The art, the concepts, sensations and movements that are generated make an audience appreciate the malleability of the human body: the elasticity and force of the body moving through space without any limits.

A sucessful dancer, with countless, extensive and rigorous exercises, must have perfected his/her body and has come to a definitive awareness of his/her body, which is a complete understanding of how the body works. Therefore, the body moves with such consciousness it looks simple and effortless. Movements in dance are the bedrock of a dancerôs work be it in practice or in performance. All of the movements are part of the language of the dancer, it is with movement through the body that intents are communicated. These movements are revealing to the audience and are revealing to the choreographer who has created them. The choreographer and dancers are a team, revealing dance as an art form. The expressions of the dancer can find the audience within his/her soul, while the choreography can locate the thoughts and emotions of the audience within a story. Dance ultimately exposes the dancer and the recipient (the audience) of their movements to 
gather an understanding from one another. The body is the vehicle for this understanding. It is exposed to the world providing a tacit language for all to understand. Doris Humphrey, according Ambrosio, states thatñwhen you move, you stand revealed for what you areò(2). Dance reveals a whole lot about individuals: whether a professional dancer is performing a choreographed piece of work or an amature dancer is moving to the rhythm of a song. We learn something about them. Dance is a revealer of the person and by extention functions as a communicator in every aspect of its being.

Despite the different benefits of dance, this article will focus on the body-mind as the core of dance therapy. The American Dance Therapy Association (ADTA) conceptualizes dance/ movement therapy as ñthe psychotherapeutic use of movement to promote emotional, social, cognitive and physical integration of the individualò (www.adta.org). A more comprehensive definition is presented by Payne. She sees dance therapy as:

é the use of expressive movement and dance as a vehicle through which an individual can engage in the process of personal integration and growth. It is founded on the principle that there is a relationship between motion and emotion and that by exploring a more varied vocabulary of movement people experience the possibility of becoming more securely balanced yet increasingly spontaneous and adaptable. Through movement and dance each personôs inner world becomes tangible; individuals share much of their personal symbolism and in dancing together relationships become visible. The dance movement therapist creates a holding environment in which such feelings can be safely expressed, acknowledged and communicated. (4)

Dance therapy is based on the principle that a vital connection exists between personality and the way in which one 
moves, and that changes in movement affects the emotional, intellectual, and physical health of the individual. It is practiced by trained dance and movement therapists who have been certified as dance movement therapists by necessary bodies like The American Dance Therapy Association (ADTA) in the United States. Dance Movement Therapy is a body-based therapy grounded in the relationship between physical movement, mental and emotional functioning, and using movement analysis and dance techniques to enhance functioning. Dance/movement therapy may include a variety of methods and is characterized by a goal-oriented, systematic treatment process. ñit is therapeutic and offers a journey of self-discovery and appreciationò (Lloyd 13). Dance/movement therapy focuses on the link between the mind and body to promote health and healing. Dance therapy is considered an expressive therapy which ultimately explores the human mind through the extensive use of the body.

It is difficult to know exactly when and for what purpose dance came into existence. However, scholars have recorded that dance started with the primitives and the purpose was basically religious. For instance, among the Shamans, dance was used for religious purposes and this informs also how it has been used as a tool for healing, thereby, laying emphasis to the importance of traditional theatrical forms. Artistic expression has been used to heal traumatized individuals since ancient times. Archibald et al observe that ñthe age-old tradition of integrating creative arts, especially music and dance, into celebrations, ceremonies, and healing rituals continues in contemporary Aboriginal culturesò (29) which, suggests that there had been an age-long practice of arts therapy, one way or the other, in traditional contexts as noticed among the Shamans. Dance therapy borrows a lot from the aboriginal form of therapy as in the case of shamanism which according to France Schott-Billmann, ñis an extension of the traditional therapies of oral cultures, which were in the form of 
rituals and where dancing and music played an important roleò(2).

Waboose posits that

Art therapy has been a tool used by Aboriginal people since time immemorial. For Aboriginal people, arts and crafts have always been an intrinsic part of our communal culture. We used art in every part of our daily lives; from making clothing to decorating ceremonial objects. We took great pride in our uniquely designed moccasins, clothing and tipis. Therefore, in an aboriginal persons eyes using art as a tool for healing would not be a foreign concept. (4)

Few scientific studies have been completed to evaluate the effects of dance therapy on health, prevention and recovery from illness. In a recent study by Gurbuz and Filiz, a group of breast cancer survivors took part in a twelve-week dance therapy and movement class. Regarding its unique connection to the field of medicine, many researches have been undertaken on the effects of dance/movement therapy in special settings with physical problems such as amputations, traumatic brain injury, and stroke, chronic illnesses such as anorexia, bulimia, cancer, Alzheimerôs disease, cystic fibrosis, heart disease, diabetes, asthma, AIDS, and arthritis (408).

Clinical reports by Karin Thulin (1997) on Colitis and Irritable Bowel Syndrome (CIBS), and Pert et al. (1985) on Neuropeptides suggest that dance therapy may be effective in improving self-esteem and reducing stress. Deihl, corroborating the reports as stated above, opines that ñthese are very real medical problems that originate in stressò (5). ñStudies have shown that physical activity is known to increase special neurotransmitter substances in the brain (endorphins), which create a state of wellbeing. And total body movement such as dance enhances the functions of other body systems, such as circulatory, respiratory, skeletal, and muscular systems.ò(Gurbuz and Filiz 15). There are extensive relevancies of dance therapy. According to Cohen et al:

Dance therapy is offered as a health promotion 
service for healthy people and as a complementary method of reducing the stress of caregivers and people with different health, emotional and psychological challenges. And, for its unique connection to the field of medicine, dance/movement therapy is a recognized form of complementary therapy used in hospitals and comprehensive clinical cancer centres. (33)

The tools of dance movement therapy can be especially useful because they unify the body and creativity as healing resources when words are not enough. The use of dance as a healing tool is rooted in the knowledge that body and mind are inseparable. Dance provides a direct experience of shared emotion on a preverbal and physical level, providing feelings of unity, harmony, and empathy. Physically, dance therapy can provide exercise, improve mobility and muscle coordination, and reduce muscle tension. As a form of exercise, dance therapy can be useful for both physical and emotional aspects of quality of life. Emotionally, dance therapy is reported to improve self-awareness, self-confidence, and interpersonal interaction, and is an outlet for communicating feelings. Some promoters of expressive therapy claim that dance therapy may strengthen the immune system through muscular action and physiological processes and can even help prevent disease. Although dance, it is thought that people can identify and express their innermost emotions, bringing those feelings to the surface. It is thought that this can create a sense of renewal, unity, and completeness and

There has been a gradual recognition of the importance of the interrelationship of the ñbodymindò and how it affects human behaviour psychologically, physically, and socially. The concepts of embodiment and attunement are becoming commonplace in the literature of various psychotherapeutic 
disciplines as well as related fields. Understanding has evolved of how illness, both physical and psychological, is by emotions. The body relays informationd our emotional historyð that remains stored in our musculature and other physiological systems. It is manifested in the individualôs postures, gestures, use of space, and movements large and small. It became clear that we cannot discard the body as a source of information, whether analogical or symbolic, or ignore it in the process of healing. The bodymind as one entity became clear to many involved in dance in conjunction with the role of creativity as a means of bodily expression. (Chaiklin and Wengrower $\mathrm{xv}$ )

The quotation above emphasizes the explanation that the body and the psyche work together. Therefore, dance therapy can only be made complete and whole with both the mind and body working holistically to get to a definite and workable solution to a patientố ailment. Dance/movement therapy is holistic; the individual is viewed as an integrated unity with mind and body reflecting and affecting each other. Inherent in this integration is the premise that muscle tone, or a balance between relaxed and tense states, affects the psychic attitude and vice versa. Dance/movement therapy theory posits that the health dysfunctional scale is reflected somatically, in the body. The theoretical foundation of dance/movement therapy is influenced by several perspectives from the field of psychology: somatic, psychodynamic, transpersonal, and interpersonal perspectives. This work, however, explores somatic practices as applied to dance therapy (DT) or dance movement therapy (DMT). In 1970, philosopher and Feldenkrais practitioner Thomas Hanna coined the term ósomaticsôfrom the Greek word óoma,ômeaning áhe body in its wholenessô The definition of somatic, and the explanation of the philosophy behind it, implies that the field understands and 
explores experience as lived and from an inner perspective (Hanna 14). The term somatic was first used by Thomas Hanna in reference to the connection between the body and the mind. Therefore, while a somatic approach recognizes that experiences can be objectively observed, these experiences must first and foremost be considered and examined from the perspective of the individual who embodies and lives out his or her own experiences (Johnson, 1995). Somatic was introduced into dance studies through extensive research and publications of Martha Myers, and further emphasized through Mary Starks Whitehouse, who through the Carl Jungôs psychoanalytic theories created her principles of dealing with clients of varying needs. This further enhanced other practitioners to develop methods in approaching dance therapy. ñSomatic practices that have been integrated readily into dance curricula include Ideokinesis, The Feldenkrais Method, the Alexander Technique, and Body-Mind Centeringò. (www.DanceEducation.org)

From a somatic perspective therefore, the integrated unity of an individual is the result of healthy development, broadly defined as the successful sequencing of the basic neurological actions that make up our earliest developmental movements. Viewed in relationship to the environment, humans develop in an organized, sequential manner. Each phase in this developmental process has somatic and physiological elements as well as psychosocial aspects. The successful and satisfactory completion of each of the phases supports healthy development and a state of health that is reflected in the body. However, body languages and gestures offer a route to mind of an individual which inadvertently gives an indication about such a person. This perspective is an important one in the treatment of traumatized individuals because of the disruption to their ability to sequence experience.

Dance movement therapy based on this premise addresses the question of identity like ñwho am Iò and self-awareness like ñwhere am I?ò Such questions channel individuals towards selfawareness and may help individuals realize the state of their psychological or physical stand-point. Through the use of movement therapy a client may gain a better understanding of 
being ultimately alone and awareness of the self as an individual (Lewis 18). Dance therapists are saddled with the responsibility for people to develop a semiotics that offer information about what is going on in the bodies and psyche of their clients. The therapist observes a person's movements to make an assessment and then designs a programme to help the specific condition. The frequency and level of difficulty of the therapy is usually tailored to meet the needs of the participants.

Dance therapy is used in a variety of settings with people who have social, emotional, cognitive, or physical concerns. These people can be individuals or groups, including entire families. Dance/movement therapy involves dealing with the conscious and the unconscious; they are dealt with separately and subsequently merged together. Consciously, it is easy to quantify time and different from the form time takes when not fully conscious: for instance when in trance or in dreams.

Although individual accounts provide most of the support for the value of dance therapy, there have been reports on how dance therapy has been used to help individuals and groups overcome issues both mentally and physically. Dance therapy helps in developing body image; improving self-concept and selfesteem; reducing stress, anxiety, and depression; decreasing isolation, chronic pain, and body tension; and increasing communication skills and feelings of well-being. Physical activity is known to increase special neurotransmitter substances in the brain, called endorphins, which create a feeling of well-being. Total body movement also enhances the functions of other body systems, such as the circulatory, respiratory, skeletal, and muscular systems. Regular aerobic exercise helps with glucose metabolism, cardiovascular fitness, and weight control. Jennifer Caputo opines that:

Physiologists have examined the functional responses and structural adaptations of the cardiovascular, respiratory, muscular, and endocrine systems to different types of physical activity. Recently, research 
interests have focused on the responses of the reproductive, skeletal, and immune systems to acute and chronic exercise. There is a branch of exercise physiology closely linked to biochemistry e.g., the chemistry of living things. (297)

Dance or movement therapy, when done regularly can confer the same benefits as other types of exercise physically. Moderate, vigorous exercise for thirty to forty-five minutes on most days of the week can reduce the risk of heart disease. Dance therapy can help people stay physically fit and experience the pleasure of creating rhythmic motions with their bodies.

\section{Marian Chace's Approach}

Chace, an experienced dance teacher began to apply the healing potency of dance to work with people who had severe mental illness (Levy, 1992). In the 1940ô Marian Chace, a staff member at the St. Elizabethôs hospital in Washington D.C., began to notice benefits in clients exposed to modern dance. Chace viewed individuals with mental illness as unique; capable of genuine interpersonal interactions and, like all human beings, long to be understood. The tenet of Marian Chaceôs approach included: 1) Body Action; 2) Symbolism; 3) Therapeutic Movement Relationship 4) Rhythmic Activity.

Chace believed that mentally ill patients communicated emotions by movement of their bodies. Bodily languages used are the suggestive actions therapists look into as a map to the mind. Certain types of movement reflect emotional blocks or expression that can be seen by a trained eye. These include musculature rigidity and movements in a rhythmic pattern. She believed that work could be done on a symbolic level. In dance therapy, the use of symbolism is to create a bridge between the familiar and the unfamiliar. Various theoretical approaches consider symbolic material differently. For those allied with psychoanalytical approaches, symbolic movement is seen as representing unconscious experience, conflicts, and defenses (Stanton and Jones 2). 
To assist with symbolism, Chace used techniques such as imagery, fantasy, recollection, verbalization and dance action to stimulate the unconscious through the conscious. With the knowledge that events of the body are stored kinesthetically in the body, this becomes possible. In order for symbolism to be effective, the client needs to be supported and accepted on an empathic level. One example of this may be taking images of trees, animals or flowers as symbols related to self, conflict or growth. Through dance, Chace perceived, reflected and reacted to her clientố emotional expressions. Chace described the therapeutic movement relationship as a deep connection of emotional acceptance, or mirroring which can be placed under the auspices of kinesthetic empathy. Fischman opines that:

Empathy is the ability of one person to understand another. It attempts to experience somebody elseôs inner life and implies knowing what the other one feels, having information about the otherôs situation and acting accordingly. It arises out of elements that are common in the experience of both individuals who are involved in the empathy process. (35)

Kinesthetic empathy therefore is the ability to understand suggestions and body languages of a client. In order to reflect the clientôs movement Chase used mirroring. In this process she took clientsô nonverbal movement seriously to connect with them and genuinely accept their emotionally states. In other words, she communicated to her clients in such a way as, ñé I hear you, I understand you and I accept youò (Levy 60). Fischman observes that:

Chace empathically involved herself in the subjective experience of the patient, joining him "where and how he is". They jointly create an environment of trust and safety that helps in 
unwinding defensive behaviors, exploring conflictive aspects of the patientôs life, and allowing spontaneous expressive movement to emerge. In this way the dance therapist is able to facilitate fluid communication with the most cut-off aspects of the clientôs self, facilitating awareness of being and becoming alive that gradually enables a socialization process. (Fischman 35)

Chace exaggerated some of these rhythmic patterns to assist the client with awareness of body language. In extreme cases Chace found that the client may slowly modify their own behaviour and ultimately be able to verbalize underlying conflicts within their self. In a nutshell the rhythmic movement relationship provided a structured environment for the clients to release genuine thoughts and feelings within a group. Chace would use her intuition to get a feel for the group by making a direct communication with each client in the beginning of the group. Chace used three interventions during her sessions. One was mirroring or empathic reflection, another was clarifying and expansion of expressive movement and the third was discussion movement. These specific techniques were used in Chaceôs work to help guide clients in a natural progression from one stage to the next (Levy 78).

\section{Mary Whitehouse's Approach}

Mary Whitehouse was another dance movement therapist who began her work in the 1950ôs. Whitehouse worked with individuals who were functioning quite well in society. Many have previously been exposed to therapy. Such clients had some basic knowledge of both psychotherapy and movement. Whitehouse facilitated both group and individual sessions to assist clients with self-discovery through movement. She used improvisation as a tool in therapy and believed that clients were who came up with the way they wanted to move expressed creativity in the session. Whitehouse valued the use of creativity through dance as a form of self- 
expression, communication and self-disclosure. Whitehouse facilitated both group and individual sessions to assist clients with self-discovery through movement. She used improvisation as a tool in therapy and believed that clients were allowed to move however they wanted to move and allow for expression for creativity during therapy sessions. Whitehouse valued the use of creativity through dance as a form of self-expression, communication and self-disclosure. Mary Whitehouseôs approach consists of several themes including: ñ1) kinesthetic awareness 2), polarity 3), active imagination 4), authentic movement and, 5) therapeutic relationship/intuitionò(Levy 71).

Whitehouse believed that kinesthetic awareness is the internal awareness of oneôs physical self. She believed that kinesthetic awareness is different for each individual and that sometimes individuals may have never developed a kinesthetic sense. In these cases the kinesthetic sense may become part of the unconscious. Kinesthetic awareness is very much concerned with a high degree of sensitivity and an understanding of how the body works and how all parts of the body connect to make and allow for synchronized involvement of all body parts. Kinesthetic awareness is concerned with the idea of understanding the movements that are being done and the fundamental knowledge of how body parts exist in relationship to each other. It is not necessarily dealing with the sensations of how the body feels or of movements, but rather the active search, through attention and sensitivity, to where the body is in space and how the body connects to itself. She refers to individuals who do have strong kinesthetic sense as being able to identify how he or she feels from one movement to another. This, Dosamantes-Alperson refers to as ñkinesthetic imagingò (19).

This approach beams a searchlight into the psyche of clients and allows for proper evaluation of the individuals situation. It encourages dance therapists to help clients see themselves in the wholesomeness of their being both of the present and the past by telling them to pay particular attention to innermost feelings and purgation of these feelings through movements. 
Whitehouse stressed the presence of polarity in the body. In the human body one body movement is the use of two set of muscles. For example while one set of muscles is contracting the other set is extending. Whitehouse believed that while a client is moving she is automatically expressing herself in polarity. Whitehouse also believed that as one type of movement is chosen by a person, the expression that was not chosen does not simply go away; it only goes unrecognized. An example of this is that a client does not stop to think of a straight movement as opposed to a curved movement.

Invisible movement is the unconscious thoughts and feelings that are expressed through the authentic movement. Whitehouse believed for a person to achieve full awareness, the individual must be able to include both conscious (authentic) and unconscious (invisible) movement (Levy 72). Whitehouse believed that the dance movement therapist needs to trust his or her own intuition, and then teach the client to trust his or her own intuition as well. She felt that the key to this approach was to meet the client where he or she is at and allow the client to forge his/her own path. The therapist needs to refrain from telling the client what he or she thinks they ñshouldò do and instead take a nondirective role allowing the client to choose. Mary Whitehouse developed what is called the Wigmaninan improvisational approach to dance. She applied Jungian thought to the therapy and was a key pioneer of dance movement therapy. She was empathic, encouraged self-awareness and self-expression through movement (Levy 78). This subsequently led to what is referred to as active imagination

Active imagination can be traced to Jungian concept of free association. It is ña natural process, a manifestation of the energy that springs from the tension of opposites, and it consists in a series of fantasy-occurrences which appear spontaneously in dreams and visionsò (Jung, 1917:79). This method is to bring both unconscious and conscious levels of thinking into the session. Whitehouse describes active imagination as allowing impulse to take form through the use of movement. She believed that one of the goals of dance movement therapy was to assist the client in 
releasing unconscious emotions that are buried in the body of the individual. These unconscious emotions are specifically located in the clientôs joints, muscles and tissues. In addition Whitehouse believed that for a client to be able to participate in the use of active imagination there needs to be an empathic environment. Active imagination therefore is the ability to consciously explore the ávould-have-beenô world to easily connect with the very person a client is. Clients are, most times, subdued by the pressure of the present therefore finding themselves in impossible positions and states which stop them from being whom they have always hoped to be. Clients are carefully guided through imaginative process which allows for fantasies and expressed as they are felt. These are unconscious emotions which she believed became "buried in the body, in tissues, muscles, and joints..." (Wallock 50). As stated above, Whitehouse being a Jungian encouraged the exploration of the conscious and unconscious in order to connect with the ñselfò of oneôs being. Jung according to Chodorow ñreestablish a relationship to that inner childò (1991:102) in order to be able to discover himself and look for possible ways out of the predicament which constantly bridled his thoughts and state of mind.

Remarkably, both approaches share some similarities in terms of the structural details of their works. Both Mary Starks Whitehouse and Marian Chace, through their different approaches acutely position their works within the theoretical framework of somatic studies. On the premise that the body and mind work together, these approaches lead to the definitive therapeutic process through integrating the conscious and the unconscious which are the tenets of dance therapy. Dance therefore being a revealer of an individual by the manner of movement gives the dance therapist the chance to accurately peek into the psychic of clients and proffer possible ways through which issues can be confronted. However, sensitivity to cultural inclinations is of great importance in movement therapy. As Johnson states: ñMy body $\ddot{i}$ its sensibilities, movement styles, reaction patterns, and health $\ddot{i}$ is not simply an individual reality governed by its own biophysical laws and idiosyncratic effects of my personal history. I am also a 
result of the ideologies within which I moveò (1993:10). Somatic approach in dance therapy is highly sensitive to the environment in which the client and the therapist may have been configured as this affects how movements are accepted and interpreted both by the client and therapist.

\section{Works Cited}

Ambrosio Nora. Learning about Dance: Dance as an Art Form and Entertainment. $7^{\text {th }}$ edition. Iowa: Kendall-Hunt Publishing, 2016.

Chaiklin, Sharon and Wengrower, Hilda (eds.).The Art and Science of Dance/Movement: Life is dance Therapy London: Routledge, 2009.

Cohen, S. O and Walco, G. A. ñDance/movement Therapy for Children and Adolescents with Cancer.ò Cancer Pract. 7 (1999):34-42.

Cohen, S. et al. ñA Global Measure of Perceived Stress.ò Journal of Health and Social Behaviour 24.4 (1983):385- 396.

Deihl, L. ñThe Dying Process Humanized Through Body Empathy.ò A Paper Presented at the American Dance Therapy Association 27th Annual Conference, October, Columbia, MD, 1992.

Dosamantes, Alperson E. ñWorking with Internalized Relationships through a Kinesthetic and Kinetic Imagery Process.ò Imagination, Cognition, and Personality 2 (1983):333-343.

Eddy, M. H. ñDance and Somatic Inquiry in Studios and Community Dance Programs.òJ Dance 2 (2002):119-127.

Fischman, D. ก̃Therapeutic Relationships and Kinesthetic Empathy.ò The Art and Science of Dance/Movement Therapy: Life is Dance. Ed. Chaiklin, S. and Wengrower, H. London: Routledge, 2009.

Gurbuz, A and Filiz, O. ñDance as a Therapy for Cancer Prevention.ò Asian Pacific Journal of Cancer Prevention 6 (2005):408-411. 
Jordan, H. ñDance/Movement Therapy.òWeb. 15 July 2016 http://faculty.wm.edu/jmchar/ Kim493/dancetherapy.html >.

Johnson, D. H. Bone, Breath, \& Gesture: Practices of Embodiment. Berkeley, CA: North Atlantic Books. 1995.

Johnson D. H. Body: Recovering our Sensual Wisdom. Berkeley, CA: North Atlantic Books, 1993.

Johnson, D. H. ñDance.ò Web. 23 Sept. 2016 <www.donhanlonjohnson.com>.

Jung, C.G. ñThe Aims of Psychotherapy.ò The Collected Works of C.G. Jung (Ws) (vol.16). Princeton: Princeton University Press, 1931.

.ñThe Transcendent Function.ò The Collected Works of C.G. Jung (2nd ed.), 8. Princeton: Princeton University Press, 1916.

- ñPsychology of the unconscious. Ò The Collected Works of C.G. Jung, vol.7. Princeton: Princeton University Press, 1917.

Levy, F. Dance Movement Therapy: A Healing Art. VA: AAHPERD Publications, National Dance Association, 1988.

Levy, J. (ed.). Dance and Other Expressive Art Therapies: When Words Are Not Enough. New York: Routledge, 1995.

Lewis, P. Theoretical Approaches in Dance-Movement Therapy. Vol. II. Iowa. Kendall/Hunt Publishing Company, 1984.

Lloyd, M. ñFunctions of Dance in the United States.ò Dance and Culture, Then and Now. 2013.

Meekums, B. Dance Movement Therapy: A Creative Psychotherapeutic Approach. Thousand Oaks : CA. Sage Publications, 2002.

Payne, H.L. (ed.) ñ̃ntroduction.ò Dance Movement Therapy: Theory and Practice. Brunner-Routledge/ Taylor \& Francis Group: Electronic Version, 2004.

Pert, C. B., et al. ñNeuropeptides and their Receptors: A Psychosomatic Network.ò Journal of Immunology 135.2 (1985): $820 і ̈ 826$. 
Schott-Billmann, F. Some Principle of Dance-Rhythm-Therapy. Paris: Courrier du Livre, 2012.

Shirl J. H., (ed). Introduction to Kinesiology: Studying Physical Activity. New York: Human Kinetics, 2009.

Stanton-Jones, K. An Introduction to Dance Movement Therapy in Psychiatry. London: Tavistock/Routledge, 1992. 